\title{
The role of quantum confinement and crystalline structure on excitonic lifetimes in silicon nanoclusters
}

\author{
L. J. Borrero-González, ${ }^{1, a)}$ L. A. O. Nunes, ${ }^{1}$ M. R. B. Andreeta, ${ }^{1}$ J. Wojcik, ${ }^{2}$ P. Mascher, ${ }^{2}$ \\ Y. A. Pusep, ${ }^{1}$ D. Comedi, ${ }^{3}$ and F. E. G. Guimarães ${ }^{1}$ \\ ${ }^{1}$ Instituto de Física de São Carlos, Universidade de São Paulo, CP 369, 13560-970 São Carlos, SP, Brazil \\ ${ }^{2}$ Department of Engineering Physics, CEDT, McMaster University, Hamilton, Ontario L8S 4L7, \\ Canada \\ ${ }^{3}$ Dep. Física, LAFISO and CONICET, FACET, Universidad Nacional de Tucumán, Av. Independencia 1800, \\ 4000 Tucumán, Argentina
}

(Received 9 March 2010; accepted 2 June 2010; published online 8 July 2010)

\begin{abstract}
The emission energy dependence of the photoluminescence (PL) decay rate at room temperature has been studied in $\mathrm{Si}$ nanoclusters $(\mathrm{Si}-\mathrm{ncl}$ ) embedded in $\mathrm{Si}$ oxide matrices obtained by thermal annealing of substoichiometric $\mathrm{Si}$ oxide layers $\mathrm{Si}_{\mathrm{y}} \mathrm{O}_{1-\mathrm{y}}, \mathrm{y}=(0.36,0.39,0.42)$, at various annealing temperatures $\left(\mathrm{T}_{\mathrm{a}}\right)$ and gas atmospheres. Raman scattering measurements give evidence for the formation of amorphous Si-ncl at $\mathrm{T}_{\mathrm{a}}=900{ }^{\circ} \mathrm{C}$ and of crystalline $\mathrm{Si}$-ncl for $\mathrm{T}_{\mathrm{a}}=1000{ }^{\circ} \mathrm{C}$ and $1100{ }^{\circ} \mathrm{C}$. For $\mathrm{T}_{\mathrm{a}}=1100{ }^{\circ} \mathrm{C}$, the energy dispersion of the PL decay rate does not depend on sample fabrication conditions and follows previously reported behavior. For lower $\mathrm{T}_{\mathrm{a}}$, the rate becomes dependent on fabrication conditions and less energy dispersive. The effects are attributed to exciton localization and decoherence leading to the suppression of quantum confinement and the enhancement of nonradiative recombination in disordered and amorphous Si-ncl. (C) 2010 American Institute of Physics. [doi:10.1063/1.3457900]
\end{abstract}

\section{INTRODUCTION}

A large variety of $\mathrm{Si}$ nanostructures have been extensively studied in the past few years due to their potential applications in Si-based light-emitting devices. A technologically important structure, which is fully complementary metal-oxide semiconductor (CMOS) compatible and takes advantage of the well-known good passivation and stability of the $\mathrm{Si} / \mathrm{SiO}_{2}$ interface, consists of crystalline silicon nanoclusters ( $\mathrm{Si}-\mathrm{ncl}$ ) dispersed in an amorphous $\mathrm{SiO}_{2}$ matrix. ${ }^{1,2}$ The mechanisms of light emission in these structures have been studied intensively. Time-resolved photoluminescence (PL) measurements have shown a nonexponential PL intensity decay in the microsecond range that can be fit by the stretched-exponential function $\mathrm{I}(\mathrm{t})=\mathrm{I}_{0} \exp \left[-(\mathrm{t} / \tau)^{\beta}\right]$, where $\mathrm{I}_{0}$ is the initial PL intensity, $\tau$ is a lifetime, and $\beta \leq 1$ is a dispersion exponent. ${ }^{3,4}$ Initially, it was suggested that the nonexponential behavior was due to exciton hopping effects combined with $\mathrm{Si}$-ncl size variations within a sample. ${ }^{5}$ Interestingly, however, it has been observed in virtually all $\mathrm{Si}$ nanostructures studied, ranging from porous silicon ${ }^{5}$ to size selected Si-ncl ensembles. ${ }^{6}$ Furthermore, the PL decay rates $(1 / \tau)$ have often been seen to increase exponentially with increasing PL emission energy according to

$$
\frac{1}{\tau}=A e^{\left(\mathrm{E}^{\mathrm{E}} \mathrm{E}_{0}\right)},
$$

where $\mathrm{A}$ is a constant, $\mathrm{E}$ is the PL emission energy, and $\mathrm{E}_{0}$ is a characteristic energy. To explain such a "universal" behavior, Delerue et al. $^{6}$ proposed a model that considered the inherent character of quantum confined excitons in indirect

${ }^{a)}$ Electronic mail: lborrero@ursa.ifsc.usp.br gap nanostructures. This model predicted $\mathrm{E}_{0}=0.31 \mathrm{eV}$, in close agreement with the reported typical experimental values $^{3-6}$ of $\mathrm{E}_{0}=0.3 \mathrm{eV}$. However, there has been a long standing debate on the role of the $\mathrm{Si} / \mathrm{SiO}_{2}$ interface states in the recombination process and the luminescence from $\mathrm{Si}-\mathrm{ncl} / \mathrm{SiO}_{2}$ materials. Moreover, the quantum confinement (QC) mechanism itself has been questioned. ${ }^{7}$ In addition, the role of the Si-ncl structure, which may be strongly disordered or even amorphous, is not well understood. Most studies have focused mainly on systems with Si-ncl possessing high degree of crystallinity. Only sparse work has been directed to disordered or amorphous $\mathrm{Si}$-ncl that may be obtained, for instance, by annealing substoichiometric Si oxide layers at relatively low temperatures $\left(<1100{ }^{\circ} \mathrm{C}\right)$.

In this work, we focus on the influence of varying Si-ncl structures on PL decay rates from Si-ncl embedded in amorphous $\mathrm{Si}$ oxides. In contrast to previous findings, we obtain $\mathrm{E}_{0}$ values much larger than $0.3 \mathrm{eV}$ that depend strongly on the fabrication conditions [i.e., the $\mathrm{Si}$ concentration in the $\mathrm{Si}$ oxide, the annealing temperature $\left(\mathrm{T}_{\mathrm{a}}\right)$, and gas atmosphere]. We propose that strong Si-ncl lattice distortion is at the origin of this effect.

\section{EXPERIMENTAL DETAILS}

The $\mathrm{Si}_{\mathrm{y}} \mathrm{O}_{1-\mathrm{y}}$ films were deposited on fused quartz substrates using an electron cyclotron resonance-plasma enhanced chemical vapor deposition system described elsewhere. ${ }^{8}$ The Si contents (y) were 0.36, 0.39, and 0.42, determined as reported previously. ${ }^{9}$ The annealing of the films was performed in a quartz tube furnace under either $\mathrm{Ar}$ or $\mathrm{Ar}+5 \% \mathrm{H}_{2}$ atmospheres for $2 \mathrm{~h}$ and at temperatures of 900,1000 , and $1100{ }^{\circ} \mathrm{C}$. These conditions lead to Si-ncl at 


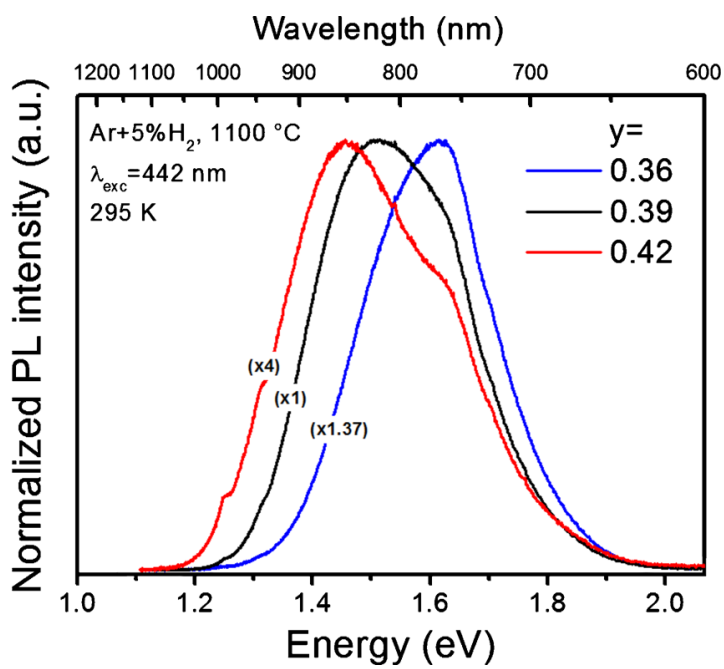

FIG. 1. (Color online) Room-temperature PL spectra for samples with y $=0.36,0.39,0.42$ (blue, black, and red lines, respectively) annealed under $\mathrm{Ar}+5 \% \mathrm{H}_{2}$ at $1100{ }^{\circ} \mathrm{C}$. The excitation wavelength was $442 \mathrm{~nm}$.

various stages of formation and $\mathrm{Si}-\mathrm{ncl} / \mathrm{SiO}_{2}$ interface defect passivation. The PL peaks that redshift in the $700-900 \mathrm{~nm}$ region with increasing $\mathrm{Si}$-ncl mean size, as can be seen in Fig. 1 for samples with $\mathrm{y}=0.36,0.39,0.42$ (blue, black, and red lines, respectively) annealed under $\mathrm{Ar}+5 \% \mathrm{H}_{2}$ at $1100{ }^{\circ} \mathrm{C}$, in qualitative agreement with the proposed excitonic QC mechanism of light emission. ${ }^{9,10}$

The optical properties of the Si-ncl were studied by using PL, confocal Raman, and time-resolved PL spectroscopies. All measurements were made at room temperature. The PL spectra were recorded by using an HR4000 Ocean Optics spectrometer as a detection system. The 442 $\mathrm{nm}$ line of a $\mathrm{He}-\mathrm{Cd}$ laser was used as the excitation source. In the Raman studies, an argon-ion laser excitation line $(514.5 \mathrm{~nm})$ was used. The decay kinetics of the luminescence were studied using the second harmonic of a Q-switch neodymium-doped yttrium aluminium garnet (Nd:YAG) laser $(532 \mathrm{~nm}, 6 \mathrm{~Hz}$ repetition rate) as the source of excitation. The excitation pulse width was 5 ns. The decay luminescence was detected by a Thermo Jarrel Ash monochromator (25 cm focal length) equipped with a Hamamatsu R928 photomultiplier tube. A digital oscilloscope processed the signal averaging over 250 pulses.

\section{RESULTS AND DISCUSSIONS}

Figure 2(a) shows Raman spectra for the six samples with $\mathrm{y}=0.42$ and thermal annealed at 900, 1000, and $1100{ }^{\circ} \mathrm{C}$ (triangles, squares, and circles, respectively) and under $\mathrm{Ar}$ (full symbols) and $\mathrm{Ar}+5 \% \mathrm{H}_{2}$ (empty symbols). By performing a multiple Gaussian fit from 100 to $550 \mathrm{~cm}^{-1}$, the TA, LA, LO, and TO phonon modes of amorphous silicon (a-Si), located at around $170 \mathrm{~cm}^{-1}, 300 \mathrm{~cm}^{-1}$, $400 \mathrm{~cm}^{-1}$, and $480 \mathrm{~cm}^{-1}$, respectively, can be deduced for the samples annealed at $900{ }^{\circ} \mathrm{C}$. The solid line represents the Gaussian fit. All spectra were normalized to the TO phonon mode. These modes are still present for samples annealed at 1000 and $1100{ }^{\circ} \mathrm{C}$. However, an additional mode appears near $516 \mathrm{~cm}^{-1}$ associated to the TO phonon mode of $\mathrm{c}-\mathrm{Si}$,

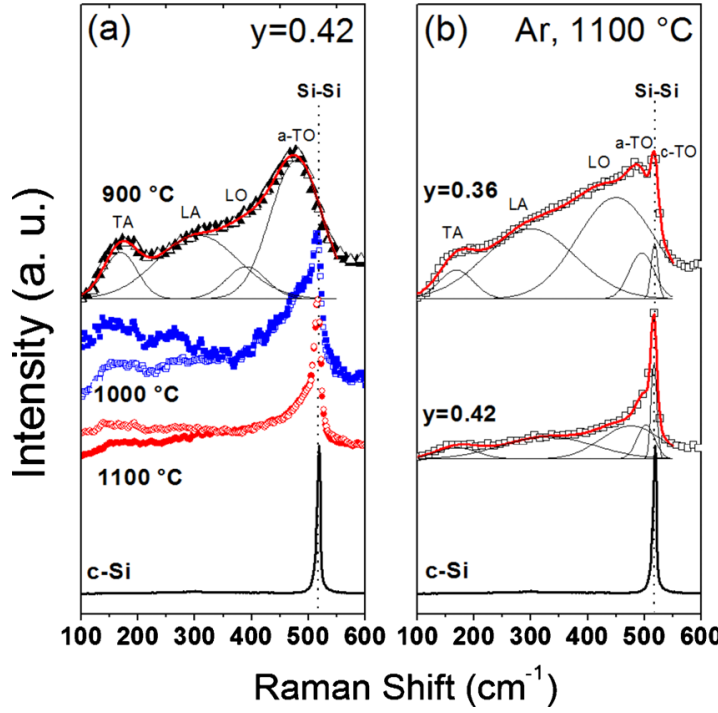

FIG. 2. (Color online) (a) Raman spectra for the samples with $y=0.42$ annealed at 900,1000 , and $1100{ }^{\circ} \mathrm{C}$ (triangle, square, and circle, respectively) under $\mathrm{Ar}$ (full symbols), and $\mathrm{Ar}+5 \% \mathrm{H}_{2}$ (empty symbols). (b) Raman spectra for the samples with Si content $\mathrm{y}=(0.36,0.42)$ annealed at $1100{ }^{\circ} \mathrm{C}$ under Ar. The Raman spectrum for the $\mathrm{c}-\mathrm{Si}$ is included in both graphs. The red lines are the Gaussian fits.

indicating crystallization processes of the amorphous phase. ${ }^{11}$ In addition, the $\mathrm{Si}-\mathrm{Si}$ Raman peak for $\mathrm{Si}-\mathrm{nc}$ is downshifted (by $\sim 2 \mathrm{~cm}^{-1}$ ) as compared to the measured Raman position in perfect c-Si $\left(518.5 \mathrm{~cm}^{-1}\right)$ in the absence of disorder and stress effects ${ }^{12}$ [see dotted vertical line in Fig. 2(a)]. The Raman spectra have nearly the same line shape for the series of samples prepared under $\mathrm{Ar}$ and $\mathrm{Ar}+5 \% \mathrm{H}_{2}$ with the same annealing temperatures. Figure 2(b) compares Raman spectra for the $\mathrm{Si}_{\mathrm{y}} \mathrm{O}_{1-\mathrm{y}}$ samples with $\mathrm{y}=0.36$ and 0.42 and $\mathrm{T}_{\mathrm{a}}=1100{ }^{\circ} \mathrm{C}$ under Ar. Again, the $\mathrm{Si}-\mathrm{Si}$ mean peak is positioned $2 \mathrm{~cm}^{-1}$ below the wave number expected for bulk $\mathrm{Si}$, indicating phonon confinement effect, ${ }^{13}$ while the line width remains at $11 \mathrm{~cm}^{-1}$. The major vibrational features of $\mathrm{a}-\mathrm{Si}$ are also present in the Raman spectra for these two samples. Note that the $\mathrm{Si}-\mathrm{Si}$ peak intensity decreases when the Si content $(\mathrm{y})$ is reduced indicating that the density and the size of Si-ncl decreases with the reduction in y. In addition, it is found that for the amorphous contribution, the integrated area diminishes, the linewidth narrows, and the peak position blueshifts when $\mathrm{T}_{\mathrm{a}}$ or $\mathrm{y}$ increase. This is probably due to the phonon confinement effect in the a-Si phase, similar to the case of crystalline Si-ncl. ${ }^{11}$ The crystalline fraction defined as $\mathrm{F}_{\mathrm{c}}=\mathrm{I}_{\mathrm{c}} /\left(\mathrm{I}_{\mathrm{c}}+\alpha \mathrm{I}_{\mathrm{a}}\right)$, where $\alpha=0.8$ is the Raman cross section ratio for phonon excitation of c-Si crystalline $\left(\mathrm{I}_{\mathrm{c}}\right)$ to the amorphous $\left(\mathrm{I}_{\mathrm{a}}\right)$ components ${ }^{14}$ increase for increasing $\mathrm{T}_{\mathrm{a}}$ or y (see Tables I and II).

TABLE I. Crystalline fractions for the samples with $\mathrm{Si}$ content $\mathrm{y}$ $=(0.36,0.42)$ annealed at $1100{ }^{\circ} \mathrm{C}$ under Ar.

Crystalline Fraction, $\mathrm{F}_{\mathrm{c}}$

Silicon content, y (\%) 
TABLE II. Crystalline fractions for the samples with $\mathrm{Si}$ content $\mathrm{y}=0.42$, annealed at 900,1000 , and $1100{ }^{\circ} \mathrm{C}$ under $\mathrm{Ar}+5 \% \mathrm{H}_{2}$.

\begin{tabular}{cc}
\hline \hline $\begin{array}{c}\text { Annealing temperature, } \mathrm{T}_{\mathrm{a}} \\
\left({ }^{\circ} \mathrm{C}\right)\end{array}$ & $\begin{array}{c}\text { Crystalline Fraction, } \mathrm{F}_{\mathrm{c}} \\
(\%)\end{array}$ \\
\hline 900 & 0 \\
1000 & $39 \pm 2$ \\
1100 & $53 \pm 1$ \\
\hline \hline
\end{tabular}

Figure 3(a) shows the PL decay curves from the $\mathrm{Si}_{\mathrm{y}} \mathrm{O}_{1-\mathrm{y}}$ samples with $\mathrm{y}=0.42$ recorded at $\mathrm{E}_{\mathrm{det}}=1.47 \mathrm{eV}$, for $\mathrm{T}_{\mathrm{a}}$ $=900,1000$, and $1100{ }^{\circ} \mathrm{C}$ (triangle, square, and circle, respectively) annealed under Ar (full symbols) and $\mathrm{Ar}$ $+5 \% \mathrm{H}_{2}$ (empty symbols). The decay behavior of the laser excitation pulse is also shown. Lines are fits of the stretchedexponential function to the experimental data, from which the $\beta$ values were determined for each sample. It can be seen that a satisfactory fit is obtained and that for the same gas atmosphere, samples annealed at high temperatures show slow kinetics when compared with samples annealed at low temperatures. In addition, for fixed $\mathrm{T}_{\mathrm{a}}$, the decay is slower for hydrogenated samples when compared with nonhydrogenated ones. This could be explained by passivation of the Si-ncl surface when hydrogen is used, eliminating nonradiative centers, such as Si dangling bonds. Figure 3(b) shows the emission energy dependence of PL decay rates for the same samples as in Fig. 3(a). At first observation, $1 / \tau$ is exponentially dependent on emission energy, $1 / \tau$ $\propto \exp \left(\mathrm{E} / \mathrm{E}_{0}\right)$, in agreement with Eq. (1). Moreover, this behavior is obeyed for all $\mathrm{T}_{\mathrm{a}}$ and both gas atmospheres used in the annealing treatments. For samples with $y=(0.36,0.39)$ we have observed the same dependence, however $\mathrm{E}_{0}$ increases with decreasing $\mathrm{T}_{\mathrm{a}}$. Figure 4 shows the emission energy dependence of PL decay rates for samples with different Si content $(y=0.36,0.39,0.42$ - triangle, circle, and square, respectively) and annealed at $1100{ }^{\circ} \mathrm{C}$ under Ar. The behavior expected from Eq. (1) is seen to be obeyed in all cases

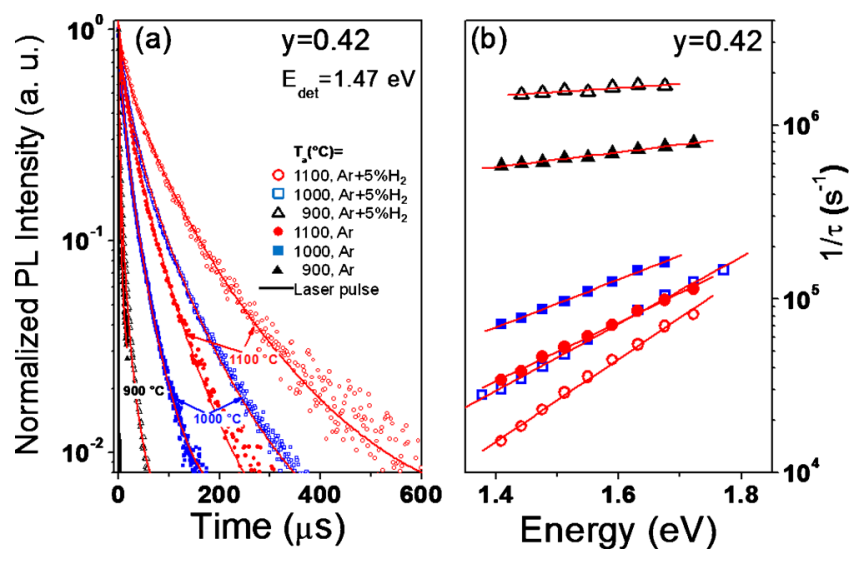

FIG. 3. (Color online) (a) PL decay curves of Si-ncl measured at $E_{\text {det }}$ $=1.47 \mathrm{eV}$ for $\mathrm{y}=0.42$. Triangles, squares, and circles corresponds to $\mathrm{T}_{\mathrm{a}}$ $=900,1000$, and $1100{ }^{\circ} \mathrm{C}$. Empty (full) symbols corresponds to hydrogenated (nonhydrogenated) samples. Lines are linear fit by using the stretchedexponential function. The laser pulse is also shown. (b) Dependence of PL decay rates on observation energy for the same samples in (a). Solid lines correspond to a linear fit by using Eq. (1).

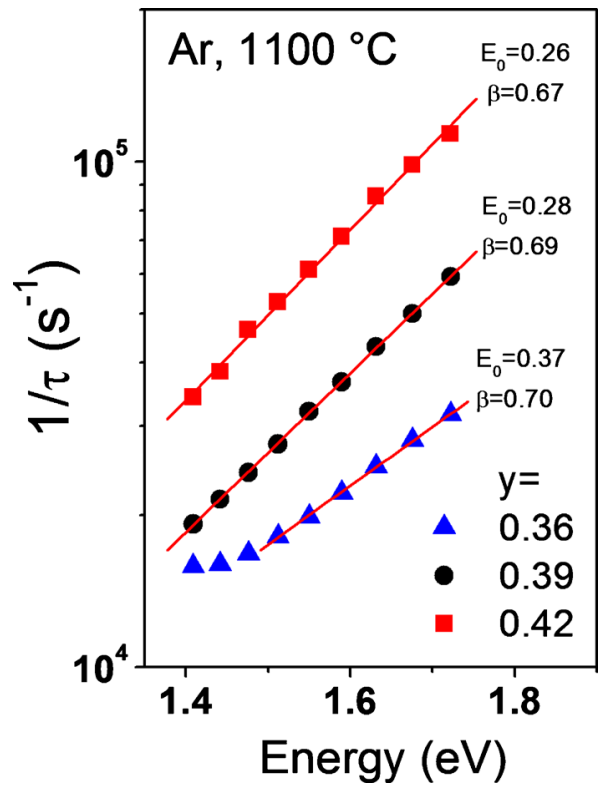

FIG. 4. (Color online) The observation energy dependence of PL decay rates at room temperature for samples with different $\mathrm{Si}$ content $\mathrm{y}$ $=(0.36,0.39,0.42$-triangle, circle, and square, respectively $)$ and annealed at $1100{ }^{\circ} \mathrm{C}$ under Ar. Solid lines correspond to a linear fit by using Eq. (1).

except for $\mathrm{y}=0.36$ at low detection energy, where the PL decay rates level off. In addition, $\mathrm{E}_{0}$ increases and the decay rates decrease with decreasing $\mathrm{Si}$ content.

These results are qualitatively similar to those reported by Pavesi ${ }^{5}$ for porous $\mathrm{Si}$, except for the fact that here the $\mathrm{E}_{0}$ parameter is not constant for samples prepared under different conditions. Garcia et al. ${ }^{15}$ studied crystalline Si-ncl embedded in $\mathrm{SiO}_{2}$ and observed almost no dependence of the PL lifetime on Si content. More recently, Derr et al. ${ }^{4}$ also observed the same dependence as in Eq. (1), with $\mathrm{E}_{0}$ $=0.3 \mathrm{eV}$ for different crystalline Si-ncl sizes.

Hence, in contrast to previous experimental reports on similar systems, our results show a clear dependence of the emission energy dependent PL decay rate, namely the $\mathrm{E}_{0}$ parameter, on the fabrication conditions. We propose that this dependence is due to the effect of Si-ncl lattice disorder, and eventually Si-ncl amorphicity, on QC and recombination kinetics. To explain the physics behind the empirical dependence of $1 / \tau$ on the emission energy [Eq. (1)], Delerue et al. ${ }^{6}$ performed combined tight-binding/valence force-field calculations of phonon-assisted optical transition matrix elements that are expected in an indirect band gap material such as $\mathrm{Si}$. In this model, the effect of QC, namely electron and hole wave function broadening in $\mathrm{k}$-space leading to increasing probability for zero-phonon transitions, ${ }^{16}$ was taken into account automatically through the electronic structure calculation in the tight-binding approach. The strong emission energy dispersion of the PL rate is then a result of the increasing electron-hole wave function overlap in k-space, which is larger at larger emission energy and affects both zero-phonon and phonon-assisted transitions. ${ }^{6}$ Therefore, the strong emission energy dispersion of the PL decay rate emerges as result of the indirect character of the Si band gap and the QC effects on the radiative transition rates, which increase with increasing emission energy (i.e., smaller Si-ncl 


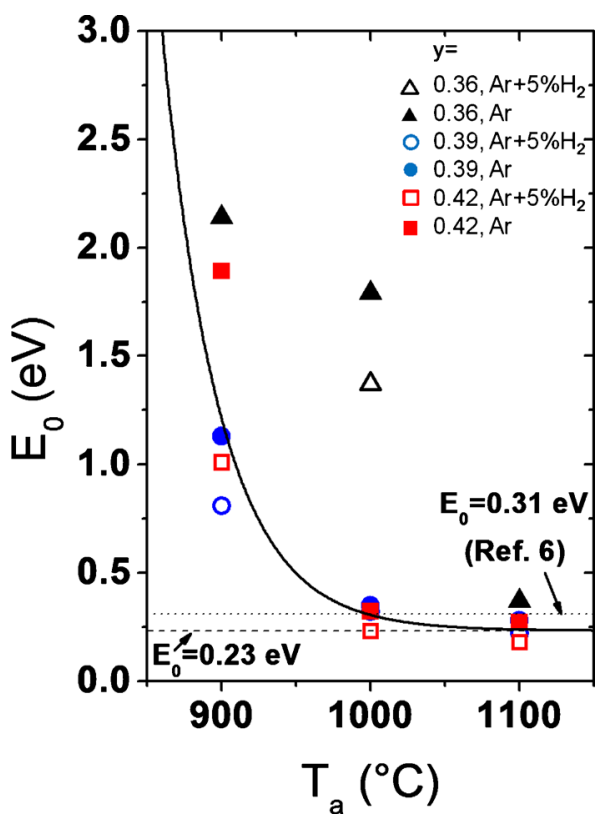

FIG. 5. (Color online) Annealing temperature dependence of $E_{0}$ for $y$ $=(0.36,0.39,0.42)$ - triangle, circle, and square, respectively. Empty (full) symbols corresponds for hydrogenated (nonhydrogenated) samples. The solid line is a guide for the eye.

size). Here, we observe that this energy dispersion becomes very small with decreasing $\mathrm{T}_{\mathrm{a}}$ for which, according to the Raman data [Fig. 2, Tables I and II], Si-ncl become disordered and contribute to a relatively large volume fraction of amorphous Si. Concomitantly, the PL decay rate becomes high [Fig. 3(b)]. Possible reasons for these effects are, on one hand, the gradual suppression of the QC in disordered Si-ncl due to disorder induced exciton localization or decoherence [in an amorphous $\mathrm{Si}$-ncl the electronic wave function coherence lengths may become as small as $1 \mathrm{~nm},{ }^{17}$ i.e., significantly smaller than the typical Si-ncl sizes of 3-6 nm (Refs. 10 and 18)]. On the other hand, in amorphous Si-ncl, the nonradiative recombination rate is expected to increase due to the typical presence of Si dangling bonds, and may eventually dominate the total PL decay rate due to the large capture cross section of these defects. ${ }^{19}$ According to Street, ${ }^{20}$ the total PL rates for bulk a-Si:H are on the order of $\sim 10^{5} \mathrm{~s}^{-1}$ at $81 \mathrm{~K}$. The larger PL rates of $\sim 5 \times 10^{5} \mathrm{~s}^{-1}$ for our samples annealed at $900{ }^{\circ} \mathrm{C}$ are comparable to those measured by Irrera et $a .^{21}$ for Si-ncl prepared at the same annealing temperature. It is interesting to note that theoretical work by Allan et al. ${ }^{22}$ for amorphous hydrogenated Si-ncl have predicted radiative rates on the same order of magnitude as those reported here, and attributed to disorderinduced breakdown of the k-conservation rule in the amorphous clusters in addition to the QC effect. Furthermore, the weak dependence on band-gap energy of the radiative rates for the amorphous Si-ncl (see Fig. 4 of Ref. 22) is in qualitative agreement with the high $\mathrm{E}_{0}$ values obtained experimentally here for the samples annealed at $900{ }^{\circ} \mathrm{C}$. This agreement is an indication that QC may still be a factor in the determination of the PL rates in the amorphous Si-ncl studied here.

A weak $\mathrm{E}_{0}$ dependence on $\mathrm{y}$ is also observed for $\mathrm{T}_{\mathrm{a}}$
$=1100{ }^{\circ} \mathrm{C}$ (see Fig. 4). In this case, $\mathrm{E}_{0}$ decreases slightly with increasing $y$, while the decay rate increases strongly. We propose that this is evidence for significant contributions of the so called "exciton hopping mechanism" to the total decay rate. Higher Si content is known to yield larger Si-ncl mean size ${ }^{10,18}$ and, as the present Raman data show [Fig. 2(b)], to larger Si-ncl density for fixed annealing conditions. Hence, exciton hopping between neighboring Si-ncl may be expected to be enhanced with increasing y. ${ }^{5}$ The decrease in $\beta$ with increasing Si content (see Fig. 4) strengthens the idea of increasing exciton hopping contributions. ${ }^{4}$

The deduced $\mathrm{E}_{0}$ values for samples prepared under the different fabrication conditions considered in this work are summarized in Fig. 5, as a function of $\mathrm{T}_{\mathrm{a}}$. The solid line is a guide for the eye. For low $\mathrm{T}_{\mathrm{a}}, \mathrm{E}_{0}$ values are relatively large for all samples and depend on the fabrication conditions. With increasing $\mathrm{T}_{\mathrm{a}}$ these values decrease significantly and become almost independent of the fabrication conditions and roughly equal to the value predicted by Delerue et $a l^{6}$ and experimentally obtained by various studies. ${ }^{3-6}$

\section{CONCLUSIONS}

The emission energy dependence of the PL decay rate at room temperature has been studied in various $\mathrm{Si}$-ncl/Si oxide samples obtained by thermal annealing at various $\mathrm{T}_{\mathrm{a}}$ in $\mathrm{Ar}$ and $\left(\mathrm{Ar}+5 \% \mathrm{H}_{2}\right)$ of substoichiometric Si oxide layers of various $\mathrm{Si}$ contents. Raman data give evidence for the formation of Si-ncl within the $\mathrm{Si}$ oxide which are essentially amorphous for $\mathrm{T}_{\mathrm{a}}=900{ }^{\circ} \mathrm{C}$ and crystalline for $\mathrm{T}_{\mathrm{a}}=1000$ and $1100{ }^{\circ} \mathrm{C}$. Equation (1) is found to be fulfilled in all cases, with the characteristic $\mathrm{E}_{0}$ value independent of fabrication conditions and in agreement with the previously reported value for $\mathrm{T}_{\mathrm{a}}=1100{ }^{\circ} \mathrm{C}$, but increasing and becoming dependent on fabrication conditions for lower $\mathrm{T}_{\mathrm{a}}$. The effects are suggested to be due to disorder induced localization and decoherence leading to the gradual suppression of QC and increasing nonradiative recombination rates in disordered and amorphous Si-ncl.

\section{ACKNOWLEDGMENTS}

We acknowledge financial support through the InterAmerican Collaboration in Materials (CIAM) initiative, from the Brazilian Agencies CNPq and FAPESP, the Argentinean CONICET and The Academy of Sciences for the Developing World (TWAS). The work at McMaster University is supported by the Natural Sciences and Engineering Research Council (NSERC), the Canadian Institute for Photonic Innovation (CIPI) and the Centre for Photonics of Ontario Centres of Excellence, Inc.

${ }^{1}$ F. Iacona, G. Franzo, and C. Spinella, J. Appl. Phys. 87, 1295 (2000).

${ }^{2}$ T. Shimizu-Iwayama, Y. Terao, A. Kamiya, and M. Takeda, Thin Solid Films 276, 104 (1996).

${ }^{3}$ M. L. Brongersma, P. G. Kik, A. Polman, K. S. Min, and H. A. Atwater, Appl. Phys. Lett. 76, 351 (2000).

${ }^{4}$ J. Derr, K. Dunn, D. Riabinina, F. Martin, M. Chaker, and F. Rosei, Physica E (Amsterdam) 41, 668 (2009).

${ }^{5}$ L. Pavesi, J. Appl. Phys. 80, 216 (1996).

${ }^{6}$ C. Delerue, G. Allan, C. Reynaud, O. Guillois, G. Ledoux, and F. Huisken, Phys. Rev. B 73, 235318 (2006). 
${ }^{7}$ L. Khriachtchev, T. Nikitin, R. Velagapudi, J. Lahtinen, and S. Novikov, Appl. Phys. Lett. 94, 043115 (2009).

${ }^{8}$ M. Boudreau, M. Boumerzoug, P. Mascher, and P. E. Jessop, Appl. Phys. Lett. 63, 3014 (1993).

${ }^{9}$ D. Comedi, O. H. Y. Zalloum, J. Wojcik, and P. Mascher, IEEE J. Sel. Top. Quantum Electron. 12, 1561 (2006).

${ }^{10}$ D. Comedi, O. H. Y. Zalloum, E. A. Irving, J. Wojcik, and P. Mascher, J. Vac. Sci. Technol. A 24, 817 (2006).

${ }^{11}$ Z.-X. Ma, X. B. Liao, G. L. Kong, and J. H. Chu, Chin. Phys. 9, 309 (2000).

${ }^{12}$ D. Bermejo and M. Cardona, J. Non-Cryst. Solids 32, 405 (1979).

${ }^{13}$ K. W. Adu, H. R. Gutierrez, U. J. Kim, G. U. Sumanasekera, and P. C. Eklund, Nano Lett. 5, 409 (2005).

${ }^{14}$ C. Smit, R. A. C. M. M. van Swaaij, H. Donker, A. M. H. N. Petit, W. M.
M. Kessels, and M. C. M. van de Sanden, J. Appl. Phys. 94, 3582 (2003).

${ }^{15}$ C. Garcia, B. Garrido, P. Pellegrino, R. Ferre, J. A. Moreno, J. R. Morante, L. Pavesi, and M. Cazzanelli, Appl. Phys. Lett. 82, 1595 (2003).

${ }^{16}$ G. Davies, Phys. Rep. 176, 83 (1989).

${ }^{17}$ R. A. Street, Hydrogenated Amorphous Silicon (Cambridge University Press, Cambridge, UK, 1991).

${ }^{18}$ D. Comedi, O. H. Y. Zalloum, E. A. Irving, J. Wojcik, T. Roschuk, M. J. Flynn, and P. Mascher, J. Appl. Phys. 99, 023518 (2006).

${ }^{19}$ M. Lannoo, C. Delerue, and G. Allan, J. Lumin. 70, 170 (1996).

${ }^{20}$ R. A. Street, Adv. Phys. 30, 593 (1981).

${ }^{21}$ A. Irrera, F. Iacona, I. Crupi, C. D. Presti, G. Franzo, C. Bongiorno, D. Sanfilippo, G. Di Stefano, A. Piana, P. G. Fallica, A. Canino, and F. Priolo, Nanotechnology 17, 1428 (2006).

${ }^{22}$ G. Allan, C. Delerue, and M. Lannoo, Phys. Rev. Lett. 78, 3161 (1997). 